\title{
ADEQUAÇÃO DO TESTE DE RAIOS X PARA AVALIAÇÃO DA QUALIDADE DE SEMENTES DE EMBAÚBA (Cecropia pachystachya Trec.) ${ }^{1}$
}

\author{
TULIO LOURENÇO PUPIM², ANA DIONISIA DA LUZ COELHO NOVEMBRE³ ${ }^{2}$ MARIA LAENE MOREIRA DE CARVALHO4${ }^{4}$, SILVIO \\ MOURE CICERO 5
}

\begin{abstract}
RESUMO - $\mathrm{O}$ trabalho foi realizado com o objetivo de adequar o teste de raios $\mathrm{X}$ para a avaliação da qualidade de sementes de embaúba e verificar a influência da formação da sua estrutura interna na germinação. As sementes foram expostas à radiação por tempos e intensidades variados, com utilização do equipamento Faxitron X-Ray, modelo MX-20 para definição da melhor combinação para visualização da morfologia interna . Definidas as condições para melhor visualização interna, as sementes foram radiografadas e classificadas em três classes, de acordo com a estrutura interna visualizada nas radiografias, em sementes totalmente formadas, parcialmente formadas e sementes não formadas. Individualmente, as sementes foram devidamente identificadas de acordo com a classe de formação e submetidas ao teste de germinação.. O teste de raios $\mathrm{X}$ é eficiente para avaliar as estruturas internas da semente de embaúba e a exposição por 360 segundos na intensidade de $10 \mathrm{kV}$ é adequada para a visualização. Há relação entre o nível de formação das sementes e os resultados do teste de germinação.
\end{abstract}

Termos para indexação: germinação, radiografia, análise de imagens.

\section{USING X-RAY TEST TO EVALUATE THE QUALITY OF EMBAÚBA SEEDS (Cecropia pachystachya Trec.)}

\begin{abstract}
The x-ray test was studied to evaluate the quality of embaúba seeds and verify the influence of the internal morphology on the seed germination. Seeds of a lot harvested in 2005 were used from the Bio Flora company. The seeds were exposed to radiation for various amounts of time and intensity, using Faxitron X-Ray equipment, model MX-20. The seeds were divided into three categories according to their internal structure visualized by radiographs in totally formed, partially formed and not formed seeds. Soon after, seeds were submitted to the germination test. The results showed that the time of 360 seconds and $10 \mathrm{kV}$ intensity are recommendable for visualizing internal seed structures. The x-ray test is efficient to evaluate development level of embaúba seed structure. There is correlation between seed formation and the germination test results.
\end{abstract}

Index terms: germination, radiography, image analysis.

${ }^{1}$ Submetido em 22/04/2007. Aceito para publicação em 17/12/2007. Monografia de conclusão de curso do primeiro autor apresentada à Universidade Federal de Lavras, UFLA. ${ }^{2}$ Graduando em Agronomia UFLA; Caixa Postal 3037, 37200-000, Lavras, MG, tuliopupim@yahoo. com.br. ${ }^{3} \mathrm{Eng}^{\circ} \mathrm{Agr}^{\circ}$, Dra., Professora Doutora, Departamento de Produção Vegetal, USP/ESALQ. Caixa Postal 09. CEP. 13418-900, Piracicaba, SP, adlcnove@esalq.usp.br. ${ }^{4}$ Eng ${ }^{\circ}$ Agro, Dra., Professora do Departamento de Agricultura, UFLA, Caixa Postal 3037, CEP 37200-000, Lavras, MG, mlaenemc@ufla.br. ${ }^{5} \mathrm{Eng}^{\circ} \mathrm{Agr}^{\circ}$, Dr., Professor Titular, Departamento de Produção Vegetal, USP/ESALQ. Caixa Postal 09. CEP. 13418-900, Piracicaba, SP, smcicero@esalq.usp.br. 


\section{INTRODUÇÃO}

Uma das técnicas empregadas atualmente no estudo da qualidade de sementes é a de raios X. Essa técnica foi estudada na Suécia, em 1953, por Simak e Gustafsson, para as sementes de Pinus sylvestris L.. Após esse estudo, esse teste tem sido aperfeiçoado para diferentes fins e espécies vegetais.

A radiografia das sementes possibilita a visualização de danos causados por insetos, fraturas ou trincas decorrentes de danos mecânicos e outros fatores provenientes da pré e pós-colheita (ISTA, 1993; Poulsen et al., 1998), a detecção de anormalidades em embriões, bem como a determinação do estádio de desenvolvimento dos mesmos (Simak, 1980; Craviotto et al., 2002; Machado, 2002; Nery, 2005).

A informação sobre a existência de sementes defeituosas e vazias é desejável, já que pode influenciar nos resultados de germinação (Craviotto et al., 2002). Pesquisa realizada por Machado (2002) indicou que o descarte de sementes com danos e anormalidades interfere positivamente na germinação das sementes.

Sementes morfologicamente perfeitas, identificadas pelo teste de raios $\mathrm{X}$, podem originar plântulas normais ou anormais e as sementes podem estar dormentes ou mortas. A variação das estruturas originadas é decorrência de condições ambientais desfavoráveis à germinação, da presença de sementes com infecções latentes, de sementes mortas por causas naturais e em estádios avançados de deterioração ou submetidas ao armazenamento inadequado (Burg et al., 1994).

$\mathrm{O}$ teste de raios $\mathrm{X}$ é útil quando realizado durante os vários processos a que as sementes são submetidas como, por exemplo, no beneficiamento, quando podem ser fisicamente alteradas e os danos não serem visíveis ao olho humano. A existência de sementes infestadas por insetos é, também, detectada na radiografia, o que pode evitar a transferência dessas sementes de uma região para a outra (Oliveira et al., 2004).

Para Cecropia pachystachya, a técnica de raios X pode ser útil para a determinação do nível de formação das sementes, no entanto, há a necessidade de adequação desse teste para a sua utilização. Dessa forma, a pesquisa foi realizada com o objetivo de adequar esse método para a avaliação da formação de sementes de embaúba e verificar a influência da morfologia interna na germinação das sementes.

\section{MATERIAL E MÉTODOS}

O trabalho foi conduzido nos Laboratórios de Análise de Imagens e de Análise de Sementes, do Departamento de Produção Vegetal, da Escola Superior de Agricultura "Luiz de Queiroz”, Universidade de São Paulo, em Piracicaba, SP. Foram utilizadas sementes de embaúba de um lote colhido em 2005, pela empresa Bio Flora.

$\mathrm{O}$ teor de água das sementes foi determinado pelo método da estufa a $105 \pm 3^{\circ} \mathrm{C}$ por 24 horas (Brasil, 1992). Os resultados, expressos em porcentagem, foram calculados com base na massa úmida $(\mathrm{Bu})$.

Para estabelecer a intensidade de radiação e o tempo de exposição das sementes, inicialmente uma amostra de 100 sementes foi distribuída em alvéolos de uma placa de acrílico $(18 \mathrm{~cm} \times 24 \mathrm{~cm})$ e radiografada em um equipamento Faxitron X-ray (modelo MX-20), por períodos de 180, 240, 300, 360 e 420 segundos, com radiações de intensidades de 10, 11, $13,15,17,20$ e $25 \mathrm{kV}$. Durante a exposição das sementes, a placa foi sobreposta ao filme radiográfico (Kodak Min-R 2000 , tamanho de $18 \mathrm{~cm} \times 24 \mathrm{~cm}$ ), distanciado a $35 \mathrm{~cm}$ da fonte emissora de radiação. Os filmes radiográficos foram revelados em processadora automática (Hope X-Ray, modelo 319 Micro-Max) e as imagens radiográficas foram digitalizadas em um scanner (Umax, modelo Power Look 1100). A imagem de cada semente foi avaliada em monitor de 21 " associado a um computador Pentium III (600MHz, memória 256Mb, HD Ultra SCSI de 20Gb).

Com base na avaliação das imagens geradas, pelas radiações e pelos períodos de exposição previamente descritos, foram estabelecidos: o tempo de 360 segundos e a intensidade de $10 \mathrm{kV}$ para radiografar as sementes.

Dessa forma, oito repetições de 25 sementes foram colocadas em alvéolos, previamente identificados por números, de placas de acrílico $(18 \mathrm{~cm} \times 24 \mathrm{~cm})$. A seguir, as sementes foram radiografadas e de acordo com a anatomia interna visualizada nas radiografias, foram consideradas três classes de sementes: totalmente formada - estruturas internas formadas e preenchendo o interior da semente; parcialmente formada - estruturas internas em diferentes estádios de desenvolvimento; não formada - nenhuma estrutura interna formada. Os resultados da classificação foram expressos em porcentagem.

Após serem radiografadas, as sementes, previamente identificadas por números, foram avaliadas quanto à germinação. A semeadura foi feita em caixas plásticas transparentes $(11 \mathrm{~cm} \mathrm{x} 11 \mathrm{~cm}$ x $3 \mathrm{~cm})$, sobre papel mata-borrão umedecido com água na proporção de 2,5 vezes a massa seca e mantidas a $30^{\circ} \mathrm{C}$, sob $8 \mathrm{~h}$ diárias de luz (Pilati et al., 1999). As avaliações foram realizadas aos 15 e aos 22 dias após 
a semeadura e os critérios considerados na avaliação foram os seguintes: plântula normal - plântula com raiz primária e hipocótilo desenvolvidos e com, no mínimo, 50\% da área das folhas cotiledonares visível; plântula anormal - plântula com raiz primária com desenvolvimento limitado e cotilédones com menos de $50 \%$ da área visível; semente não germinada - sementes sem nenhuma estrutura visível desenvolvida.

\section{RESULTADOS E DISCUSSÃO}

O teor de água das sementes influencia a densidade ótica, assim, quanto menor a quantidade de água das sementes, maior a densidade ótica, o que possibilita a diferenciação adequada das estruturas das sementes visualizadas nas radiografias (Simak, 1991). Dessa forma, é recomendável a padronização do teor de água das sementes para a realização do teste de raios X. As sementes de embaúba avaliadas tinham $10 \%$ de água.

A exposição das sementes aos raios $\mathrm{X}$, em intensidades de radiação de $10,11,13,15,17,20$ e $25 \mathrm{kV}$ e por períodos de 180, 240, 300, 360 e 420 segundos, indicou 360 segundos e $10 \mathrm{kV}$ como a condição mais favorável para o exame das estruturas internas das sementes, como pode ser observado na Figura 1. Nessa condição foi possível determinar o nível de desenvolvimento das estruturas internas da semente, bem como outro tecido denso ao redor do embrião, com coloração clara e nítida, que é o tegumento da semente. Autores como Simak (1991) e Bino et al. (1993) relataram que, nas radiografias, as áreas escuras correspondem às áreas de tecidos da semente em que há penetração dos raios $\mathrm{X}$, enquanto que as claras representam as partes mais densas da semente. Com base nesse contexto, não houve possibilidade de identificar as estruturas do embrião, uma vez que a semente totalmente formada tinha o mesmo grau de radiopacidade.

De acordo com os resultados obtidos no teste de

\section{FIGURA 1. Imagens radiográficas de sementes de embaúba: totalmente formada (a); parcialmente formada (b); não formada (c).}

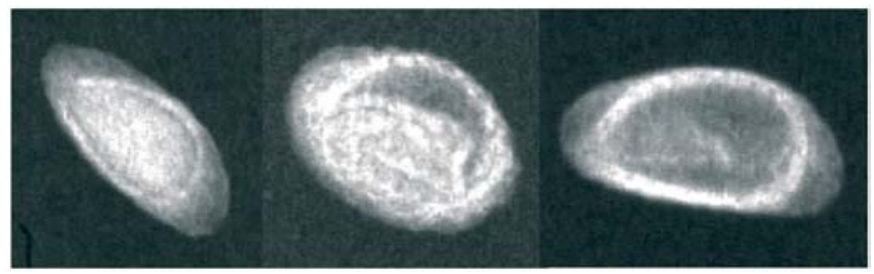

(a)

(b)

(c) germinação, as sementes classificadas como totalmente formadas originaram plântulas normais, plântulas anormais ou sementes não germinadas (Tabela 1 e Figura 2). Esse tipo de resultado é esperado para esse teste, pois, na radiografia, as imagens indicam se há ou não tecidos formados mas, não estabelecem,necessariamente, relação diretacomos processos fisiológicos da semente. Burg et al. (1994) indicaram que algumas sementes com características adequadas no teste de raios X não germinam, provavelmente, devido à infecção por microrganismos, à deterioração fisiológica ou à morte dos tecidos.

FIGURA 2. Plântulas e sementes de embaúba obtidas no teste de germinação: plântula normal (a); plântula anormal (b); semente não germinada (c).

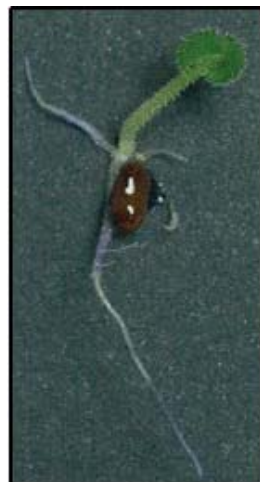

(a)

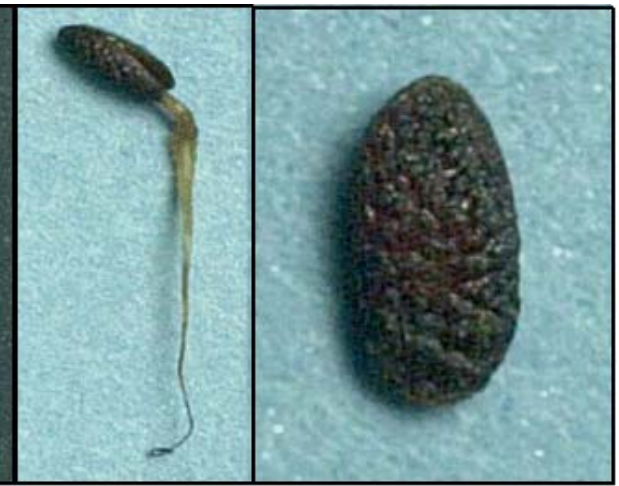

(b) (c)
TABELA 1. Classificação das sementes de embaúba, totalmente formada (TF), parcialmente formada (PF) e não formada (NF) e germinação das sementes, plântula normal (PN), plântula anormal (PA) e semente não germinada (NG), submetidas ao teste de raios X. USP/ESALQ, Piracicaba, SP, 2005.

\begin{tabular}{ccccc}
\hline Classe & Total de se- & \multicolumn{3}{c}{ Germinação (\%) } \\
\cline { 3 - 5 } & classe (\%) & PN & PA & NG \\
\hline TF & 61,5 & 66,67 & 8,94 & 24,39 \\
PF & 25 & 0,00 & 4,00 & 96,00 \\
NF & 13,5 & 0,00 & 0,00 & 100,00 \\
\hline
\end{tabular}


A correspondência entre as imagens radiográficas e as plântulas ou sementes, originadas no final do período de germinação (Figura 3), indicou que a maior parte das sementes classificadas como totalmente formadas, originou plântulas normais, as sementes classificadas como parcialmente formadas originaram plântulas anormais e todas as sementes não formadas originaram sementes não germinadas. Essa variação de resultados deve-se, provavelmente, às diferenças de maturação, comum em espécies florestais, pois essas sementes são colhidas em vários estádios de desenvolvimento do embrião (Tonetti, 2004). Nesse sentido, o beneficiamento de sementes de embaúba, para eliminar as mal formadas, contribui para estabelecer níveis superiores de germinação para essas sementes. Os resultados dessa pesquisa indicaram que a classificação das sementes de embaúba, com base nas radiografias, foi eficiente.

FIGURA 3. Imagens radiográficas de sementes de embaúba e respectivas plântulas ou sementes no final do período de germinação: (a) semente totalmente formada e plântula normal; (b) semente parcialmente formada e plântula anormal; (c) semente não formada e semente não germinada.

(a)
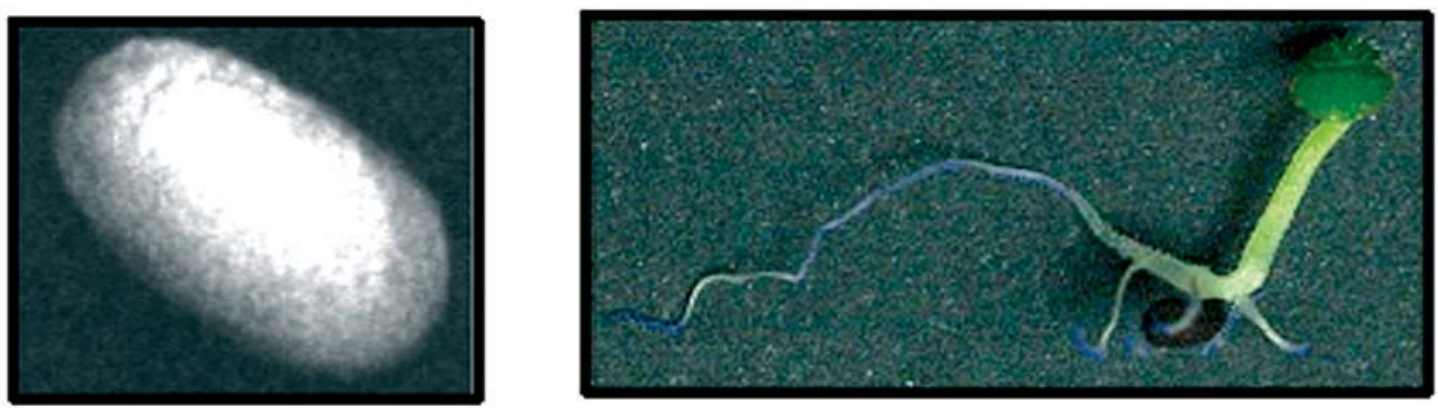

(b)
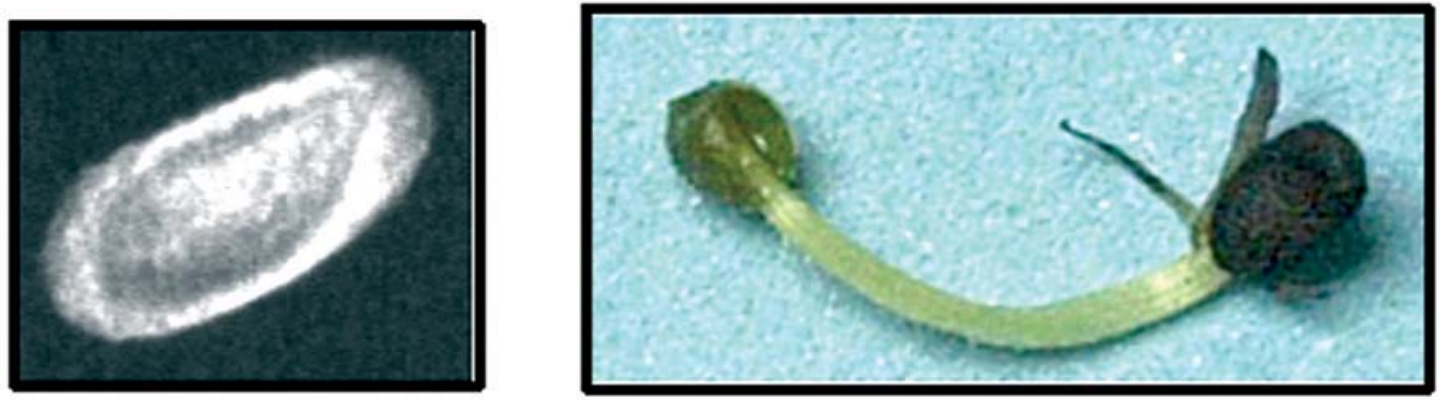

(c)

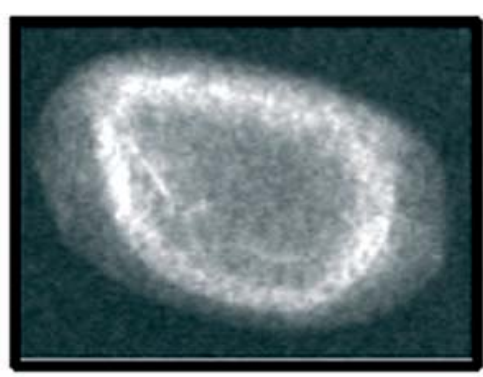

CONCLUSÕES

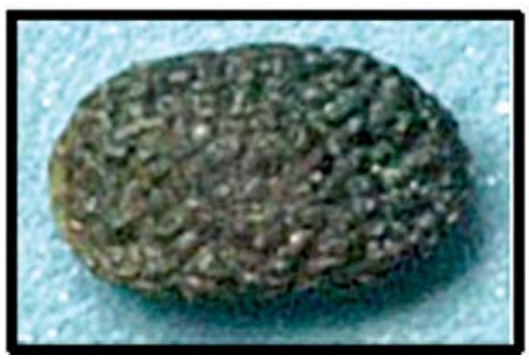

REFERÊNCIAS

BINO, R.J.; AARTESE, J.W.; BURG, W.J. van der. Nondestructive X-ray of Arabidopsis embryo mutants. Seed Science Research, Wallingford, v.3, n.2, p.167-170, 1993. 
BRASIL. Ministério da Agricultura e Reforma Agrária. Regras para análise de sementes. Brasília, DF: SNDA/ DNDV/CLAV, 1992. 365p.

BURG, W.J. van der; AARTESE, J.W.; ZWOL, R.A. van; JALINK, H.; BINO, R.J. Predicting tomato seedling morphology by x-ray análisis of seeds. Journal of American Society for Horticultural Science, Alexandria, v.119, n.2, p.258-263, 1994.

CRAVIOTTO, R.M.; YOLDJIAN, A.M.; SALINAS, A.R.; ARANGO, M.R.; BISARO, V.; MATURO, H. Description of pure seed fraction of oat through usual evaluations and radiographic images. Pesquisa Agropecuária Brasileira, Brasília, DF, v.37, n.8, p.1183-1188, 2002.

INTERNATIONAL rules for seed testing. Seed Science and Technology, Zurich, v.21, 363p., 1993. Suplement.

MACHADO, C.F. Metodologia para a condução do teste de germinação e utilização de raios $X$ para a avaliação da qualidade de sementes de Aroeira-branca (Lithraea molleoides (Vell.) Engl.). 2002. 51f. Dissertação (Mestrado em Fitotecnia) - Escola Superior de Agricultura "Luiz de Queiroz"/Universidade de São Paulo, Piracicaba.

NERY, M.C. Aspectos morfológicos do desenvolvimento de sementes de Tabebuia serratifolia Vahl Nich. 2005. 95f. Dissertação (Mestrado em Fitotecnia) - Universidade Federal de Lavras, Lavras.

OLIVEIRA, L.M.; CARVALHO, M.L.M.; GUIMARÃES, R.M.; MASETTO, T.E. Avaliação da qualidade de sementes de Tabebuia serratifolia Vahl Nich. e T.impetiginosa(Martius
Ex A. P. De Candolle Standley) - (Bignoniaceae) pelo teste de raios X. Revista Brasileira de Sementes, Brasília, DF, v.26, n.2, p.138-143, 2004.

PILATI, R.; ANDRIAN, I.F.; CARNEIRO, J.W.P. Effects of different temperatures on the performance of seeds germination of Cecropia pachystachya Trec. Brazilian Archives of Biology and Technology, Curitiba, v.42, n.2, p.195-204, 1999.

POULSEN, K.M.; PARRATT, M.J.; GOSLING, P.G. (Ed.). Tropical and subtropical tree and shrub seed handbook. Zurich: International Seed Testing Assiciation, 1998. 204p.

SIMAK, M. X-radiography in research and testing of forest tree seeds. Umea Swedish University of Agriculture Science: [S.1.]: Department of Silviculture, 1980, 34p. (Report, 3).

SIMAK, M. Testing of forest tree and shrub seeds by X-radiography. In: GORDON, A.G.; GOSLING, P.; WANG, B.S.P. Tree and shrub seed handbook. Zurich: ISTA, 1991. p.1-28.

SIMAK, M.; GUSTAFSSON, A. X-ray photography and sensitivity in forest tree species. Hereditas, Landskroma, v.39, n.3/4, p.458-468, 1953.

TONETTI, O.A.O. Melhoria da qualidade física e estudo da germinação de sementes dea candeia (Eremanthus incanus (Less.) Less. e Eremanthus erythropappus (DC.) Mac Leish). 2004. 81f. Dissertação (Mestrado em Engenharia Florestal) - Universidade Federal de Lavras, Lavras. 